\title{
Cyclin-dependent kinase 1 inhibitor RO3306 promotes mitotic slippage in paclitaxel-treated HepG2 cells
}

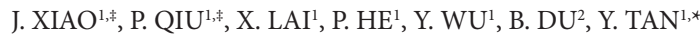 \\ ${ }^{1}$ Department of Biochemistry, Guangzhou University of Chinese Medicine, Guangzhou, China; ${ }^{2}$ Department of Pathology, Guangzhou University \\ of Chinese Medicine, Guangzhou, China \\ *Correspondence: yuhuitan@yeah.net \\ ${ }^{*}$ Contributed equally to this work.
}

Received April 4, 2013 / Accepted May 14, 2013

\begin{abstract}
Hepatocellular carcinoma (HCC) is the most common primary liver neoplasm and current systemic chemotherapy are mostly ineffective. Paclitaxel (PTX) has a clinically significant effect on many malignant tumors. Cells treated with PTX undergo reversible mitotic arrest and although high doses can cause side effects it may also induce apoptosis. We investigated the effect of a sequential combination of PTX and RO3306, a cyclin-dependent kinase 1 inhibitor, on the hepatocellular carcinoma HepG 2 cell line. The sequential drug treatment protocol involved the addition of PTX $(0.2 \mu \mathrm{mol} / \mathrm{L})$ for $18 \mathrm{~h}$ followed by RO3306 $(2 \mu \mathrm{mol} / \mathrm{L})$ for a further $6 \mathrm{~h}$. Cell viability and proliferation were measured using tetrazolium dye (MTT) and colony formation assay. Cell cycle profiles were established by flow cytometry. The expression level of protein was examined by immunoblotting. We observed a synergistic effect of PTX and RO3306 treatment on cell growth and proliferation as well as an increased proportion of cells in sub-G1 phase. Expression levels of cyclin B, cyclin E and phosphorylated Histone H3 demonstrated that RO3306 enhanced apoptosis in PTX treated cells by mitotic slippage. Our data suggested that the combination of PTX and RO3306 may be an effective therapeutic combination for the treatment of liver cancer.
\end{abstract}

Key words: paclitaxel, RO3306, apoptosis, mitotic slippage, HepG2 cells

HCC is a malignant tumor with high morbidity and mortality [1]. Although several therapeutic approaches can be used for the treatment of HCC, including surgery, radiotherapy and chemotherapy, patients prognosis remains unsatisfactory and more efficacious therapies are required [2]. Modulation of the apoptotic response of cancer cells has remained one of the central therapeutic strategies against cancer [3, 4].

PTX has a clinically significant effect on many malignant tumors and works by stabilizing the microtubule polymer, inhibiting spindle formation and promoting the occurrence of mitotic arrest leading to abnormal mitosis [5, 6]. Arresting cancer cells at the mitotic phase has effect that is dependent on the dose and duration of drug treatment. Transient mitotic arrest is reversible, and upon removal of the drug, cells re-enter the cell cycle without the induction of apoptosis. Although persistent drug treatment at high concentration can cause side effect, it may also trigger cellular apoptosis. Under conditions of high stress, cells under mitotic arrest aberrantly exit mitosis without chromosomal segregation or cytokinesis and enter into the tetraploid G1 phase (pseudo-G1 phase). This may lead to programmed cell death. This process, termed mitotic slippage, is required for the induction of apoptosis following mitotic arrest [7]. We hypothesized that cells treated with PTX in combination with an inhibitor of mitosis, in the form of a CDK1 inhibitor, would be forced to enter the pseudo-G1 phase and hence initiate apoptosis.

The cell cycle is driven by cyclin-dependent kinases (CDKs) in combination with cyclins. The CDK1/cyclin B complex is required for successful mitosis, inactivation of the mitotic kinase CDK1 forces the cell to exit the cell cycle [8]. We tested whether RO3306, a CDK1 inhibitor, accelerated mitotic slippage and enhance the induction of apoptosis following PTX treatment.

\section{Materials and methods}

Materials. PTX injection was purchased from Bristol-Myers Squibb (Sermoneta-Latina, Italy). RO3306 was purchased 


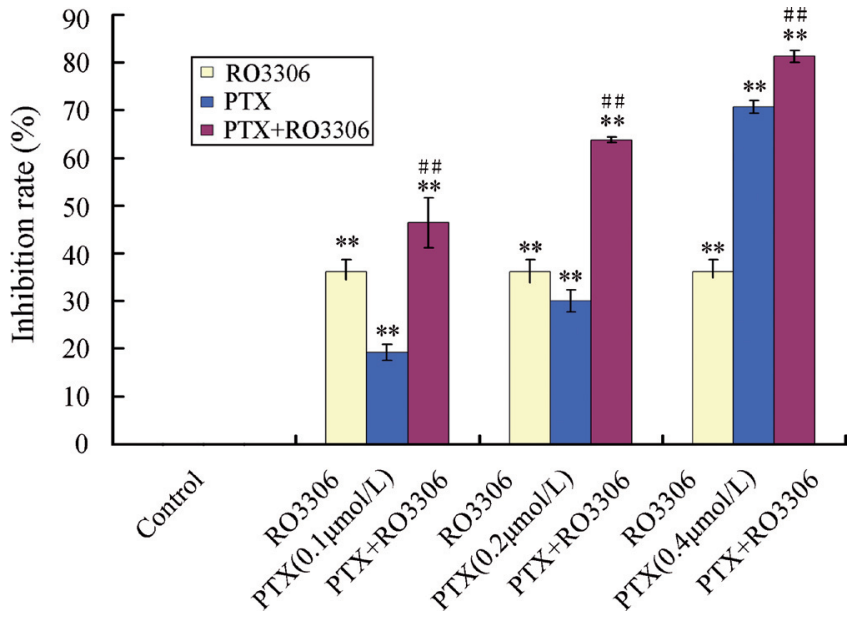

Figure 1. Combinatorial treatment of HepG2 cells with PTX and RO3306 had a synergistic effect on cell viability. HepG2 cells were treated with drugs of which PTX includes three concentrations $(0.1,0.2$ and $0.4 \mu \mathrm{mol} / \mathrm{L}$, respectively). Cell viability was measured by the MTT assay. The data are presented as the mean \pm standard deviation. ${ }^{\star *} \mathrm{p}<0.01$ compared with control; ${ }^{\# \#} \mathrm{p}<0.01$ compared with PTX or RO3306 treatment alone.

from Enzo Life Sciences (NY, USA). MTT and propidium iodide (PI) were purchased from Sigma Chemical Co. (St. Louis, MO, USA). Monoclonal anti-cyclin B1 (sc-245), polyclonal anti-cyclin E (sc-198), and monoclonal anti-Bcl-2 (sc-509) were purchased from Santa Cruz Biotechnology, Inc., Santa Cruz, CA, USA. Polycolonal anti-Bax antibody (2772) and monoclonal anti-actin (ms-1295-po) were purchased from Cell Signaling Technology, Inc. (MA, USA) and NeoMarkers (Fremont, CA, USA), respectively.

Cell culture. The HCC cell line, HepG2, was obtained from Sun Yat-sen University Cell Collection and cultured in Dulbecco's modified Eagle's medium supplemented with $10 \%$ fetal bovine serum and $100 \mathrm{U} / \mathrm{mL}$ penicillin/streptomycin.

Drug treatment. Cells were treated with either of the single agents, PTX $(0.2 \mu \mathrm{mol} / \mathrm{L})$ or RO3306 $(2 \mu \mathrm{mol} / \mathrm{L})$, for 24 or $6 \mathrm{~h}$, respectively. The sequential drug treatment protocol involved the addition of PTX for $18 \mathrm{~h}$ followed by RO3306 for a further $6 \mathrm{~h}$.

MTT assay. HepG2 cells were seeded in 96-well plates with $1 \times 10^{3}$ cells/well and incubated for overnight in $100 \mu \mathrm{L}$ culture medium. Cells were treated with drugs of which PTX includes three concentrations $(0.1,0.2$ and $0.4 \mu \mathrm{mol} / \mathrm{L}$, respectively). MTT $[100 \mu \mathrm{L}(5 \mathrm{~g} / \mathrm{L})]$ was added to the cells which were then cultivated for a further $4 \mathrm{~h}$. Following the removal of the medium from the wells, $100 \mu \mathrm{L} /$ well of DMSO was added to the cells and agitated for $15 \mathrm{~min}$. Absorbance was measured at $570 \mathrm{~nm}$ using an ELISA reader (Bio-rad 550, USA). Untreated HepG2 cells were used as a control. Assays were performed in triplicate.

Colony formation assay. HepG2 cells $\left(5 \times 10^{2}\right.$ cells/well $)$ were seeded in 6-well plates and incubated overnight. Follow- ing the drug treatment, cells were washed out the compounds, and incubated in drug free medium for 7 days. Cells were then fixed with a mixture of methanol: acetic acid (3:1) for $15 \mathrm{~min}$ at room temperature and stained by Giemsa for $15 \mathrm{~min}$ at room temperature. Following extensive washing with $\mathrm{H}_{2} \mathrm{O}$, photos were taken and colonies consisting of at least 50 cells were scored.

Cell cycle analysis. HepG2 cells $\left(5 \times 10^{4}\right.$ cells/well $)$ were grown in 6-well plates followed by drug treatment. After $24 \mathrm{~h}$ drug exposure, the cells were trypsinized, washed twice with cold PBS and centrifuged at $5000 \mathrm{rpm}$ for $5 \mathrm{~min}$ at $4^{\circ} \mathrm{C}$. The cell pellet was resuspended in $1 \mathrm{~mL}$ cold PBS and fixed in $9 \mathrm{~mL}$ of $70 \%$ ethanol at $-20^{\circ} \mathrm{C}$ for at least $12 \mathrm{~h}$. Cells were centrifuged at $5000 \mathrm{rpm}$ for $5 \mathrm{~min}$ at $4^{\circ} \mathrm{C}$ and resuspended in $500 \mu \mathrm{L}$ PBS. PI staining buffer was added in the dark at room temperature for $30 \mathrm{~min}$ and subsequently analyzed by FACS (FACStar cytofluorometer, BD Biosciences).

Immunoblotting. HepG2 cells were grown and treated as for the flow cytometry assay. Following drug treatment, cells were washed twice with PBS and lysed in RIPA buffer [0.5 M Tris- $\mathrm{HCl}(\mathrm{pH} 7.4), 1.5 \mathrm{M} \mathrm{NaCl}, 2.5 \%$ deoxycholic acid, 10\% NP-40, 10 mM EDTA] (20-188, Upstate, CA, USA). Proteins were separated by electrophoresis on $12 \%$ SDS polyacrylamide-gel, transferred to a PVDF (Polyvinylidene Fluoride) membrane, immunostained with appropriate antibody and visualized. The primary antibodies and dilutions used were cyclin B1 (1:500), cyclin E (1:500), Bax (1:1,000), Bcl-2 (1:1,000) and $\beta$-actin (1:2,000). The secondary antibodies used were anti-rabbit $(1: 10,000)$ and anti-mouse $(1: 5,000)$.

Statistical analysis. All data were expressed as the mean \pm standard deviation and analyzed by SPSS 11.0 software (SPSS Inc. Chicago, IL, USA). Data analysis was performed using t-tests and $\mathrm{P}<0.05$ was considered statistically significant. *significance compared with control; "significance compared with PTX or RO3306 treatment alone. Statistical significance is indicated in the graphs by one symbol for $\mathrm{p}<0.05$, two symbols for $\mathrm{p}<0.01$.

The combination effect of drugs was assessed with $Q$ value, $\mathrm{Q}=\mathrm{E}_{\mathrm{AB}} /\left[\mathrm{E}_{\mathrm{A}}+\mathrm{E}_{\mathrm{B}}\left(1-\mathrm{E}_{\mathrm{A}}\right)\right]\left(\mathrm{E}_{\mathrm{A}}, \mathrm{E}_{\mathrm{B}}\right.$ and $\mathrm{E}_{\mathrm{AB}}$ indicated the effects of $\operatorname{drug} \mathrm{A}$, drug $\mathrm{B}$ and the combination of two drugs). According to "Q" value, the combination effect between two drugs can be classified as an antagonistic effect $(\mathrm{Q}<0.85)$, an additive effect $(0.85<\mathrm{Q}<1.15)$, or a synergistic effect $(\mathrm{Q}>1.15)$.

\section{Results}

Combined treatment with PTX and RO3306 had a synergistic effect on HepG2 cell viability. The viability of the human HCC cell line HepG2 following treatment with PTX and RO3306 alone and in combination was assessed using the MTT assay. Cells were cultured followed by drug treatment of which PTX includes three concentrations $(0.1,0.2$ and $0.4 \mu \mathrm{mol} / \mathrm{L}$, respectively). After $\mathrm{RO} 3306$ treatment alone, only a small inhibition of viability was observed (36.14\%). Although PTX treatment alone had some cytotoxicity for the cells (19.78\%, 
$30.00 \%$ and $70.79 \%$ ), the inhibition rate was significantly increased when cells were cultured with PTX and RO3306 together $(46.45 \%, 63.82 \%$ and $81.38 \%$, respectively) ( $\mathrm{p}<0.01$ ) (Figure 1). The combination effect of PTX and RO3306 was assessed with Q value (0.952, 1.154 and 1.003 , respectively). These results demonstrate treatment of HepG2 cells with PTX $(0.2 \mu \mathrm{mol} / \mathrm{L})$ in combination with $\mathrm{RO} 3306$ had a synergistic effect compared to either agent alone $(\mathrm{Q}>1.15)$.

Combinatorial treatment of HepG2 cells with PTX and RO3306 had a synergistic inhibitory effect on colony formation. As anticancer drugs generally inhibit cell proliferation, we next examined the combinatorial effect of PTX $(0.2 \mu \mathrm{mol} /$ L) and RO3306 on the proliferation of HepG2 cells using a colony formation assay. The inhibition of colony formation following treatment with PTX or RO3306 alone was 25.68\% and $15.83 \%$, respectively. Combinatorial treatment with PTX and RO3306 inhibited colony formation by $63.35 \%(\mathrm{p}<0.01)$ (Figure 2). This demonstrated that, in combination, the drugs had a synergistic effect on the proliferation of HepG2 cells compared to the single agents $(\mathrm{Q}=1.69>1.15)$.

Cell cycle profile of HepG2 cells treated with a combination of PTX and RO3306. To establish the effect of PTX and RO3306 combination on the growth of HepG2 cells we used flow cytometry to analyze the distribution of cells in the cell cycle. As seen in Figure 3, an increased proportion of cells were

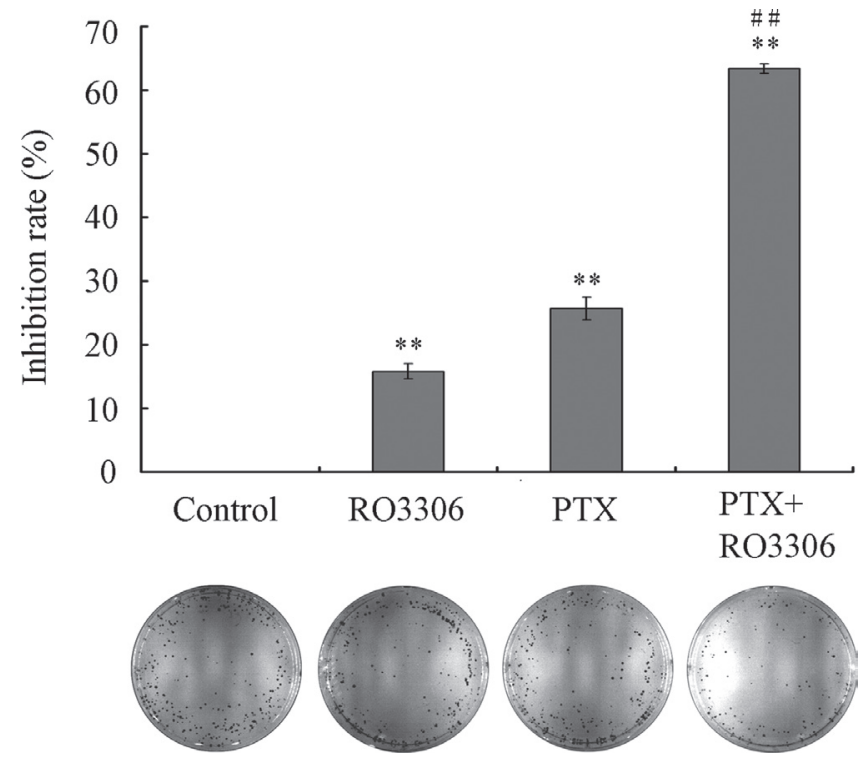

Figure 2. Combined treatment of HepG2 cells with PTX and RO3306 had a synergistic inhibitory effect on colony formation. HepG2 cells were cultured in drug free medium for 7 days followed by drug treatment. After fixation and Giemsa staining, photos were taken and colonies that consisted of at least 50 cells were counted. Bars represent the standard deviations. ${ }^{* *} p<0.01$ compared with control; ${ }^{\# \#} \mathrm{p}<0.01$ compared with PTX or RO3306 treatment alone.
Control

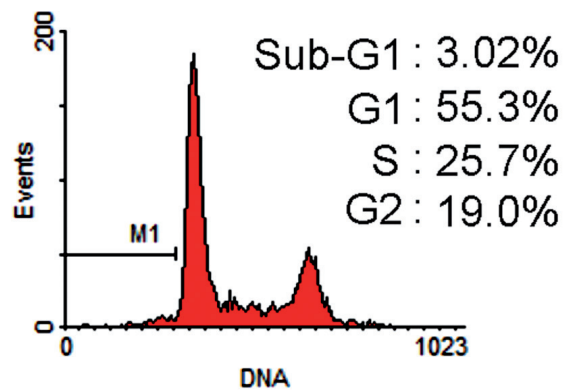

PTX

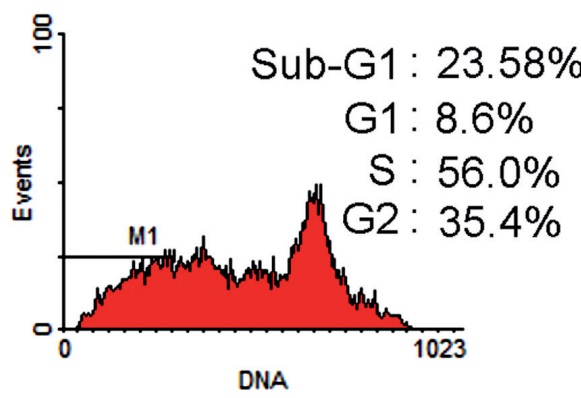

RO3306

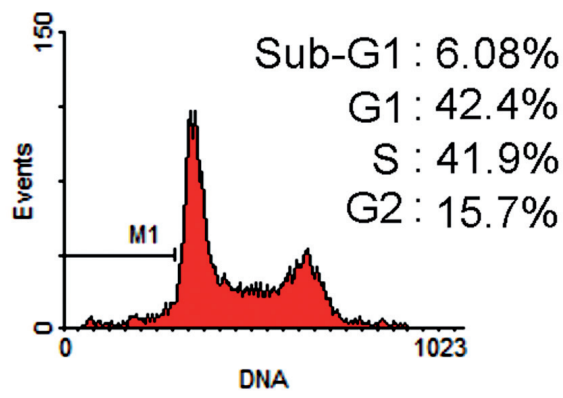

PTX+RO3306

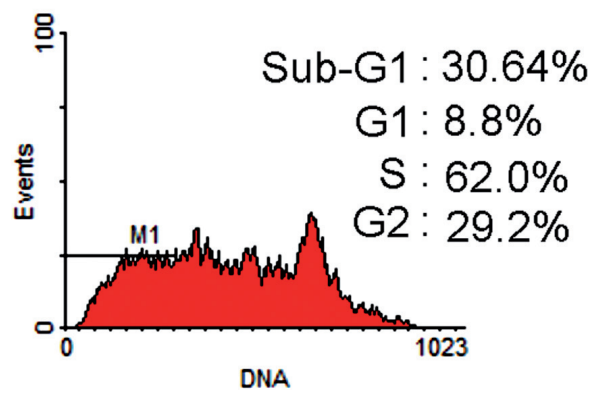

Figure 3. Cell cycle profile of HepG2 cells following drug treatment. Drug-treated HepG2 cells were stained with PI and DNA content was analyzed by flow cytometry. 

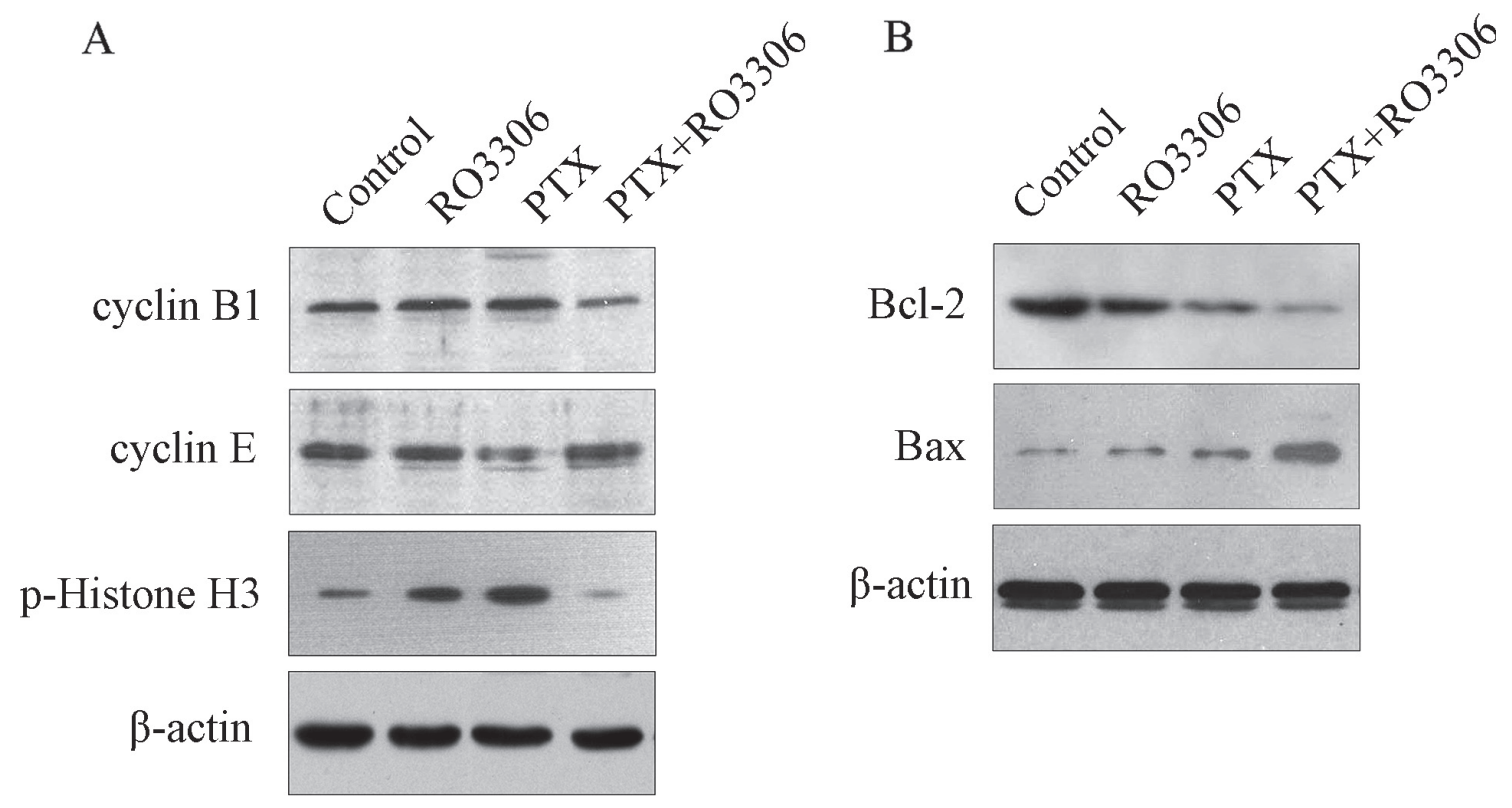

Figure 4. Changes in gene expression patterns after drug treatment. Drug-treated HepG2 cells were lysed and the expression levels of cyclin E, cyclin B1, p-Histone $\mathrm{H3}$ (A), Bcl-2 and Bax (B) were determined by immunoblotting.

observed in the sub-G1 phase following treatment with PTX $(0.2 \mu \mathrm{mol} / \mathrm{L})$ at $23.58 \%$. Furthermore, the proportion of cells in $\mathrm{G} 2 / \mathrm{M}$ phase increased to $35.4 \%$. Combinatorial treatment of HepG2 cells with PTX and RO3306 increased the proportion of cells in the sub-G1 phase by $7.06 \%(\mathrm{Q}=1.20>1.15)$, which showed synergism. In contrast, the proportion of cells in the G2/M phase decreased by $6.2 \%$. These results indicated that RO3306 enhanced the proportion of apoptotic cells treated with PTX by increasing the proportion of cells in sub-G1 phase and reducing the amount of cells in the G2/M phase.

Gene expression pattern demonstrated cell cycle arrest, mitotic slippage and apoptosis following combinatorial treatment of HepG2 cells with PTX and RO3306. Cyclin expression changes depending on the division phase of the cell and this pattern can be used to define the position of a cell within the cell cycle [9]. For example, the association of cyclin $\mathrm{E}$ with CDK2 at the G1/S transition allows the cell to enter the $S$ phase and the association of CDK1 with cyclin B is necessary for mitosis to occur. We used this knowledge to examine the expression level of cyclins in HepG2 cells following combined treatment with PTX and RO3306. Treatment of HepG2 cells with PTX $(0.2 \mu \mathrm{mol} / \mathrm{L})$ alone resulted in the upregulation of cyclin B1 and downregulation of cyclin E (Figure 4A). This result was consistent with the cell cycle profile in which treatment with PTX increased the proportion of cells in the mitotic arrest. Treatment with a combination of PTX and RO3306 resulted in the downregulation of cyclin B1, which indicated that the HepG2 cells had exited mitosis. Furthermore, the upregulation of cyclin E suggested that cells may subsequently enter the G1 phase after leaving the $\mathrm{M}$ phase (Figure $4 \mathrm{~A}$ ). However, this was inconsistent with the cell cycle profile results in which there were only a small number of cells in G1 phase, whereas an appreciable number of cells in the G2/M phase compared to the controls. Therefore, the sequential, combinatorial treatment of HepG2 cells with PTX and RO3306 caused cells to enter into a pseudo-G1 phase with 4 N DNA.

To determine whether RO3306 promoted mitotic slippage in PTX treated cells, we measured the phosphorylation of histone H3 (p-Histone H3) which is considered to be a crucial event for the onset of mitosis [10]. Treatment with PTX alone resulted in a considerable increase in the level of p-Histone H3 (Figure 4A). In contrast, cells treated with PTX followed by RO3306 showed decreased levels of p-Histone H3. This indicated that RO3306 promoted mitotic slippage in cells treated with PTX.

Cells that persist in the pseudo-G1 phase are prone to enter the programmed cell death pathway. We therefore measured whether the expression level of anti-apoptotic $\mathrm{Bcl}-2$ protein and pro-apoptotic Bax protein, which are involved in mitochondrial apoptosis, were altered after combined drugs treatment. In cells treated with a combination of PTX and RO3306, we observed a decrease in Bcl-2 and an increase in Bax expression compared with treatment alone (Figure 4B). This indicated that a combination of PTX and RO3306 resulted in the increased induction of apoptosis compared to treatment with single agents.

\section{Discussion}

PTX is thought to induce mitotic arrest or apoptosis depending on the extent of drug damage $[11,12]$. Cells with 
Control

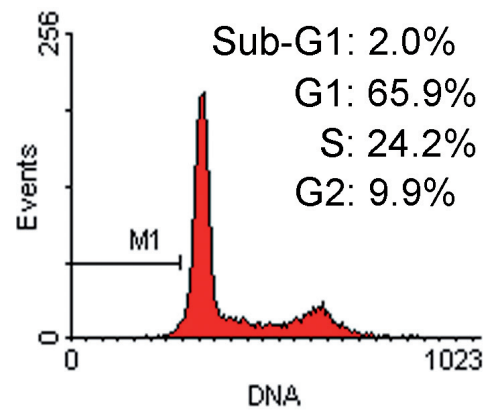

RO3306+PTX

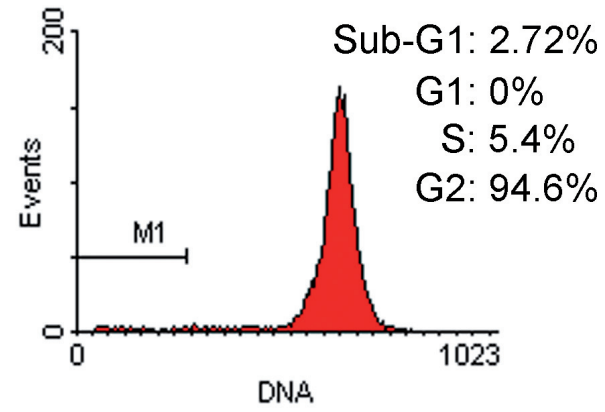

Figure 5. The effect of reversed sequential treatment (RO3306 followed by PTX) on HepG2 cells. Cells were cultured in the medium supplemented with PTX $(0.2 \mu \mathrm{mol} / \mathrm{L})$ and RO3306 $(0.2 \mu \mathrm{mol} / \mathrm{L})$ for $6 \mathrm{~h}$. Then, the culture medium was replaced by new medium containing PTX $(0.2 \mu \mathrm{mol} / \mathrm{L})$. After additional $18 \mathrm{~h}$, cells were trypsinized and collected for flow cytometry with PI stain.

slight insult of PTX will pass mitotic arrest and re-enter the subsequent cell cycle phase without the induction of apoptosis. Under the persistent PTX insult, afflicted cells will undergo the apoptotic program by mitotic slippage. It was suggested that mitotic slippage is necessary for apoptosis to take place in cells under mitotic arrest [7]. We therefore hypothesized that we could increase apoptosis by facilitating mitotic slippage [13]. The inactivation of the mitotic kinase CDK1 is known to facilitate the release of cells from mitosis [8]. Thus, treatment with RO3306, a novel and selective CDK1 inhibitor, may force cells that are damaged by PTX to escape mitosis. Here, we showed that a sequential combination of PTX and RO3306 (a CDK1 inhibitor) act synergistically to inhibit growth and induce apoptosis in HepG2 cells. These data suggested that combinatorial treatment with PTX and RO3306 increased drug sensitivity of HepG2; when used together, these drugs may provide a promising new anti-HCC therapeutic combination.

However, not all CDK1 inhibitors act to enhance apoptosis in PTX-treated cells. In fact, the inhibition of CDK1 using a chemical inhibitor, dominant negative CDK1 or a cyclin B1 antisense oligonucleotide, prevented the induction of apoptosis by PTX $[14,15]$. To explain this discrepancy, the premature activation of CDK1 has been shown to be required for apoptosis induced by anti-microtubule agents such as PTX [16]. As the inhibition of CDK1 arrested cells mainly at the G2/M border of the cell cycle, CDK1 inhibition prior to PTX therapy enables cells to escape PTX-imposed mitotic arrest in HepG2 cells leading to reduced cellular apoptosis. In support of this hypothesis, we investigated the apoptotic effect of reversed sequential treatment (RO3306 followed by PTX) and observed that the percentage of apoptotic cells was dramatically reduced (Figure 5). This data highlighted the importance of treating with PTX followed by RO3306 in order that mitotic arrest and slippage can sequentially take place.

The cell cycle profile showed that PTX treatment increased the proportion of cells in the M phase in a dose-dependent manner. This is also consistent with the upregulation of cyclin $\mathrm{B}$ which is specifically highly expressed in M phase. However, sequential, combinatorial treatment with PTX and RO3306 increased the fraction of cells in the sub-G1 phase. This suggested that RO3306 enhanced apoptosis in PTX-treated cells. Although the fraction of HepG2 cells at G2/M phase decreased following combinatorial treatment, the percentage of cells in G1 phase diminished. This was inconsistent with the finding of cyclin E upregulation, which is active at the G1/S transition. Furthermore, the considerable proportion of tetraploid cells with low expression levels of cyclin B suggested that cells that exited $M$ phase slipped into G1 phase with $4 \mathrm{~N}$ DNA (the so-called pseudo-G1 phase). It is known that p-Histone $\mathrm{H} 3$ is highly expressed at the $\mathrm{M}$ phase of the cell cycle. Therefore, to confirm that combinatorial treatment of HepG2 cells caused mitotic slippage, the expression level of p-Histone $\mathrm{H} 3$ was examined [10]. An increase in p-Histone $\mathrm{H} 3$ following PTX treatment indicated that HepG2 cells were arrested in the $\mathrm{M}$ phase. In contrast, cells treated with RO3306 for $6 \mathrm{~h}$ showed decreased levels of p-Histone H3, which suggested that RO3306 promoted mitotic slippage, although considerable amount of cells were found to be tetraploid. Taken together, these results supported our hypothesis that RO3306 acts in synergy with PTX to induce apoptosis through the promotion of mitotic slippage.

Notably, pseudo-G1 cells might provoke cell demise by activating a p53-mediated tetraploid checkpoint [17]. Under this hypothesis, the induction of apoptosis by PTX and RO3306 may depend on wild-typed p53 in cells. Presumably, p53 mutation which frequently occurs in HCC may attenuate the efficacy of these agents. However, the possibility was negated by the data that p53-deficient cells remained sensitive to KSP inhibitor-induced cell death, which suggested that the induction of apoptosis following mitotic slippage may not depend on the p53-mediated tetraploid checkpoint [18]. To confirm this result, further study that involves p53-deficient cell line such as Hep3B $\left(\mathrm{p} 53^{--}\right)$was warranted. 


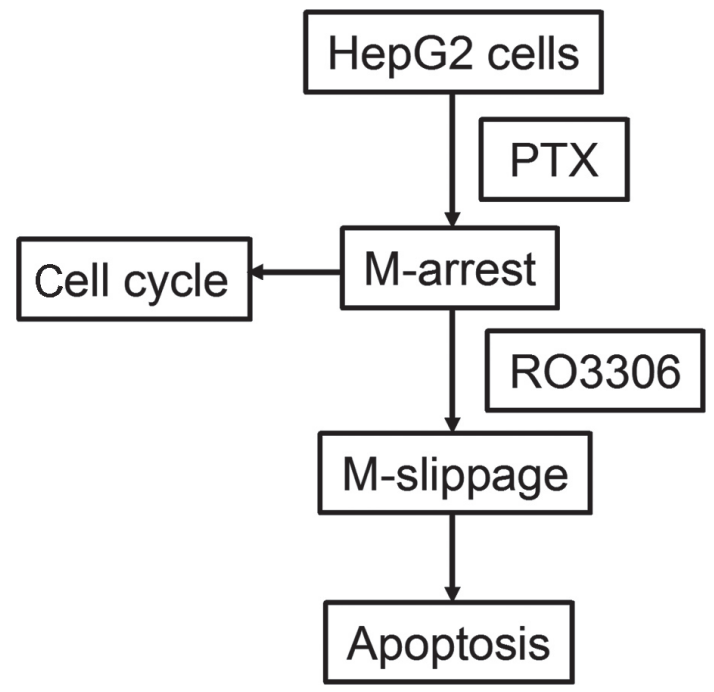

Figure 6. Schematic representation of the mechanism of apoptosis induced by PTX and RO3306 in HepG2 cells. PTX, paclitaxel.

Mitotic slippage is thought to induce apoptosis by activating the pro-apoptotic protein Bax $[7,19]$. The expression level of Bax was shown to be significantly upregulated in HepG2 cells following treatment with PTX and RO3306. We also investigated the Bcl-2 expression level and showed it to be downregulated in HepG2 cells after combined treatment with PTX and RO3306. This was consistent with our cell cycle results which showed an increase in the percentage of sub-G1 cells. These results demonstrated that PTX, in combination with RO3306, induced apoptosis in HepG2 cells through a mitochondrial cell death pathway.

Our report suggested that apoptosis induced by mitotic antagonism via mitotic arrest and slippage is a novel anti-cancer therapeutic approach (Figure 6) [7, 13,20]. Consequently drugs that promote mitotic slippage may act in synergy with PTX in tumor cells to promote apoptosis. Future research should focus on generating a wider variety of CDK inhibitors able to accelerate mitotic slippage and improve the anticancer efficacy of mitotic antagonists, such as PTX.

Acknowledgements: This work was supported by grants from the National Natural Science Foundation of China (Nos. 30973811 and 81274145), Guangdong Natural Science Foundation (No. S2012040007005), Guangdong Provincial Administration of Chinese Traditional Medicine (No. 20121227) and Ministry of Education, Science Technology Development Center (No. 20124425120012)

\section{References}

[1] EL-SERAG HB. Hepatocellular carcinoma. N Engl J Med 2011; 365: 1118-1127. http://dx.doi.org/10.1056/NEJMra1001683

[2] MAJNO P, LENCIONI R, MORNEX F, GIRARD N, POON $\mathrm{RT}$ et al. Is the treatment of hepatocellular carcinoma on the waiting list necessary? Liver Transpl 2011; 17 Suppl 2: S98-108. http://dx.doi.org/10.1002/lt.22391

[3] KYPRIANOU N, MARTIKAINEN P, DAVIS L, ENGLISH HF, ISAACS JT. Programmed cell death as a new target for prostatic cancer therapy. Cancer Surv 1991; 11: 265-277.

[4] KYPRIANOU N, BAINS AK, JACOBS SC. Induction of apoptosis in androgen-independent human prostate cancer cells undergoing thymineless death. Prostate 1994; 25: 66-75. http://dx.doi.org/10.1002/pros.2990250203

[5] RICOTTI L, TESEI A, DE PAOLA F, MILANDRI C, AMADORI D et al. Potentiation of antiproliferative drug activity by lonidamine in hepatocellular carcinoma cells. J Chemother 2003; 15: 480-487.

[6] PANVICHIAN R, ORTH K, DAY ML, DAY KC, PILAT MJ et al. Paclitaxel-associated multimininucleation is permitted by the inhibition of caspase activation: A potential early step in drug resistance. Cancer Res 1998; 58: 4667-4672.

[7] TAO W. The mitotic checkpoint in cancer therapy. Cell Cycle 2005; 4: 1495-1499. http://dx.doi.org/10.4161/cc.4.11.2130

[8] ANDREASSEN PR, MARGOLIS RL. Microtubule dependency of p34cdc2 inactivation and mitotic exit in mammalian cells. J Cell Biol 1994; 127: 789-802. http://dx.doi.org/10.1083/ jcb.127.3.789

[9] SCHWARTZ GK, SHAH MA. Targeting the cell cycle: A new approach to cancer therapy. J Clin Oncol 2005; 23: 9408-9421. http://dx.doi.org/10.1200/JCO.2005.01.5594

[10] CROSIO C, FIMIA GM, LOURY R, KIMURA M, OKANO $\mathrm{Y}$ et al. Mitotic phosphorylation of histone h3: Spatio-temporal regulation by mammalian aurora kinases. Mol Cell Biol 2002; 22: 874-885. http://dx.doi.org/10.1128/MCB.22.3.874$\underline{885.2002}$

[11] GALLAGHER BM Jr. Microtubule-stabilizing natural products as promising cancer therapeutics. Curr Med Chem 2007; 14: 2959-2967. http://dx.doi.org/10.2174/ 092986707782794014

[12] CASADO P, PRADO MA, ZUAZUA-VILLAR P, DEL VALLE E, ARTIME N et al. Microtubule interfering agents and ksp inhibitors induce the phosphorylation of the nuclear protein $\mathrm{p} 54(\mathrm{nrb})$, an event linked to $\mathrm{g} 2 / \mathrm{m}$ arrest. J Proteomics 2009; 71: 592-600. http://dx.doi.org/10.1016/ j.jprot.2008.09.001

[13] GALAN-MALO P, VELA L, GONZALO O, CALVO-SANJUAN R, GRACIA-FLETA L et al. Cell fate after mitotic arrest in different tumor cells is determined by the balance between slippage and apoptotic threshold. Toxicol Appl Pharmacol 2012; 258: 384-393. http://dx.doi.org/10.1016/ j.taap.2011.11.021

[14] YU D, JING T, LIU B, YAO J, TAN M et al. Overexpression of erbb2 blocks taxol-induced apoptosis by upregulation of p21cip1, which inhibits p34cdc2 kinase. Mol Cell 1998; 2: 581-591. http://dx.doi.org/10.1016/S1097-2765(00)80157-4

[15] SHEN SC, HUANG TS, JEE SH, KUO ML. Taxol-induced p34cdc2 kinase activation and apoptosis inhibited by 12 o-tetradecanoylphorbol-13-acetate in human breast mcf-7 carcinoma cells. Cell Growth Differ 1998; 9: 23-29.

[16] SHI L, NISHIOKA WK, TH'NG J, BRADBURY EM, LITCHFIELD DW et al. Premature p34cdc2 activation required 
for apoptosis. Science 1994; 263: 1143-1145. http://dx.doi. org/10.1126/science.8108732

[17] MARGOLIS RL, LOHEZ OD, ANDREASSEN PR. G1 tetraploidy checkpoint and the suppression of tumorigenesis. J. Cell. Biochem 2003; 88: 673-683. http://dx.doi.org/10.1002/ jcb. 10411

[18] TAO W, SOUTH VJ, ZHANG Y, DAVIDE JP, FARRELL L, et al. Induction of apoptosis by an inhibitor of the mitotic kinesin KSP requires both activation of the spindle assembly checkpoint and mitotic slippage. Cancer Cell 2005; 8: 49-59. http://dx.doi.org/10.1016/j.ccr.2005.06.003

[19] BLAGOSKLONNY MV. Mitotic arrest and cell fate: Why and how mitotic inhibition of transcription drives mutually exclusive events. Cell Cycle 2007; 6: 70-74. http://dx.doi. org/10.4161/cc.6.1.3682

[20] ZHU LH, BI W, LIU XD, LI JF, WU YY et al. Induction of apoptosis by evodiamine involves both activation of mitotic arrest and mitotic slippage. Oncol Rep 2011; 26: 1447-1455. 